\title{
NUMERICAL STUDY OF A TRIANGULAR FIN INSERTED IN A SQUARE CAVITY WITH UPPER SLIDING SURFACE SUBJECTED TO A MIXED CONVECTION EFFECT
}

\author{
A. L. Razera ${ }^{a}$, \\ T. M. Fagundes ${ }^{\mathrm{a}}$, \\ R. J. C. Fonseca ${ }^{a}$, \\ L. Z. Lessa ${ }^{a}$, \\ A. Schmidt ${ }^{\mathrm{a}}$, \\ G. M. Furtado ${ }^{a}$, \\ E. D. Santos ${ }^{\mathrm{b}}$, \\ L. A. Isoldi ${ }^{\mathbf{b}}$, \\ and L. A. O. Rocha \\ ${ }^{a}$ Universidade Federal do Rio Grande do Sul \\ Escola de Engenharia \\ R. Sarmento Leite, $n^{\circ} 425$, Centro Histórico \\ CEP 90050-170, Porto Alegre, RS, Brasil \\ razera.andre@gmail.com \\ ${ }^{\mathrm{b}}$ Universidade Federal de Rio Grande \\ Escola de Engenharia \\ Av. Itália, km 8, Carreiros \\ CEP 96203-900, Rio Grande, RS, Brasil \\ ABSTRACT \\ This article investigates numerically, using the Constructal Design method, \\ a system that combines a square cavity with upper sliding wall and a \\ triangular fin subjected to the mixed convection effect. The objectives are to \\ evaluate the influence of the fin aspect ratio (H1/L1) on the average Nusselt \\ number on the fin surface and to analyze the effect of the fraction of the area \\ of the triangular fin relative to the square cavity $(\phi)$. The proposed problem \\ is assumed two-dimensional, laminar, incompressible and steady flows. For \\ the buoyancy forces it is considered the Boussinesq approximation. In order \\ to generalize the results, the problem is solved in dimensionless form. The \\ fluid flowing through the cavity presents the thermophysical properties \\ defined by the Prandtl number $(\mathrm{Pr}=0.71)$. The buoyancy force in the flow \\ is defined by the Rayleigh number $(\mathrm{RaH}=104)$, while the flow regime is \\ governed by the Reynolds number $(\mathrm{ReH}=102)$. The optimum fin geometry \\ that maximizes the heat transfer between the finned cavity and the \\ surrounding fluid is obtained through the Constructal Design method. The \\ numerical solution of the conservation equations of mass, momentum and \\ energy is calculated with the finite volume method, using the commercial \\ fluid dynamics software FLUENT®. The geometry and mesh computational \\ domain were developed in GAMBIT ${ }^{\circledR}$ package. As results, it was found \\ that the optimal configurations of H1/L1 presented a gain in the thermal \\ performance of up to $15 \%$ in relation to the other geometries. In addition, \\ the heat transfer has great dependence on the variation of the fraction of area \\ $(\phi)$. \\ Received: May 25, 2017 \\ Revised: June 19, 2017 \\ Accepted: July 17, 2017 \\ Keywords: constructal design, mixed convection, Nusselt number, square \\ cavity, triangular fin

\section{NOMENCLATURE} \\ A total area of the cavity, $\mathrm{m}^{2}$ \\ $\mathrm{A}_{\mathrm{f}} \quad$ fin area, $\mathrm{m}^{2}$ \\ $\mathrm{C}_{\mathrm{p}}$ fluid specific heat at constant pressure, \\ $\mathrm{J} /(\mathrm{kg} . \mathrm{K})$ \\ g gravitational acceleration, $\mathrm{m} / \mathrm{s}^{2}$ \\ $\mathrm{h}$ heat transfer coefficient $\left(\mathrm{W} / \mathrm{m}^{2} . \mathrm{K}\right)$ \\ $\mathrm{H}$ cavity height, $\mathrm{m}$ \\ $\mathrm{H}^{*} \quad$ dimensionless cavity height \\ $\mathrm{H}_{1} \quad$ fin height, $\mathrm{m}$ \\ $\mathrm{H}_{1}^{*} \quad$ dimensionless fin height \\ k fluid thermal conductivity, W/(m.K) \\ L cavity length, $\mathrm{m}$ \\ $\mathrm{L}^{*} \quad$ dimensionless cavity length \\ $\mathrm{L}_{1} \quad$ fin length, $\mathrm{m}$ \\ $\mathrm{L}_{1}^{*} \quad$ dimensionless fin length \\ $\mathrm{Nu}_{\mathrm{H}} \quad$ Nusselt number based on the height \\ $\overline{\mathrm{Nu}_{\mathrm{H}}}$ average Nusselt number based on the height \\ $\mathrm{P} \quad$ pressure, $\mathrm{Pa}$ \\ Pr Prandtl number \\ q” conductive heat flux per unit of area, $\mathrm{W} / \mathrm{m}^{2}$ \\ $\mathrm{Ra}_{\mathrm{H}} \quad$ Rayleigh number based on the height \\ $\mathrm{Re}_{\mathrm{H}} \quad$ Reynolds number based on the height \\ $\mathrm{S}$ surface on which the fluid flows, $\mathrm{m}^{2}$ \\ $\mathrm{S}^{*} \quad$ dimensionless surface \\ $\mathrm{T}$ absolute temperature, $\mathrm{K}$ \\ $\mathrm{T}^{*} \quad$ dimensionless temperature \\ $\mathrm{T}_{\max }$ maximum temperature, $\mathrm{K}$ \\ $\mathrm{T}_{\text {min }}$ minimum temperature, $\mathrm{K}$ \\ $\mathrm{T}_{\infty} \quad$ reference temperature, $\mathrm{K}$ \\ $\mathrm{u} \quad$ velocity in direction $\mathrm{x}, \mathrm{m} / \mathrm{s}$ \\ $\mathrm{u}^{*} \quad$ dimensionless velocity in direction $\mathrm{x}$ \\ $\mathrm{v}$ velocity in direction $\mathrm{y}, \mathrm{m} / \mathrm{s}$ \\ $\mathrm{v}^{*}$ dimensionless velocity in direction $\mathrm{y}$ \\ $\mathrm{V}$ velocity of the upper moving wall of the \\ cavity, $\mathrm{m} / \mathrm{s}$ \\ $\mathrm{x}, \mathrm{y} \quad$ spatial coordinates, $\mathrm{m}$ \\ $\mathrm{x}^{*}, \mathrm{y}^{*}$ dimensionless spatial coordinates
}




\section{Greek symbols}

$\alpha \quad$ thermal diffusivity, $\mathrm{m}^{2} / \mathrm{s}$

$\beta \quad$ thermal expansion coefficient, $\mathrm{K}^{-1}$

$\phi \quad$ fraction of the area of the triangular fin relative to the square cavity

$\mu \quad$ fluid dynamic viscosity, $\mathrm{kg} /(\mathrm{m} . \mathrm{s})$

$v \quad$ fluid kinematic viscosity, $\mathrm{m}^{2} / \mathrm{s}$

$\rho$ density, $\mathrm{kg} / \mathrm{m}^{3}$

\section{Subscripts}

\section{max maximum \\ min minimum \\ o optimal}

\section{INTRODUCTION}

Heat transfer is an extremely important area in many engineering problems. Applications of advanced technologies and research on heat transfer have expanded from traditional fields of industry such as mechanical, chemical and energy engineering to new fields, such as electronics and space areas. Thus, the current heat transfer problems appear with high heat density, mainly in compact problems of micro and nanoscale.

Convection is the heat transfer process executed by a fluid flow (Bejan, 1993). The process of heat transfer by convection can occur in forced form, where an external agent acts on the fluid and causes it to flow; or in the natural form, in which the movement is caused by the effects of buoyancy, which acts distributed in the fluid, and is associated with the general tendency of fluids to expand when heated under constant pressure [Bejan and Kraus, 2003]. The presence of the fluid temperature gradient in the gravitational field gives rise to natural convection currents; thus, forced convection is accompanied by natural convection (Çengel and Ghajar, 2009).

One way to increase heat transfer by convection is by inserting fins (outer extended surfaces) or cavities (internal extended surfaces) into the bodies in which heat removal is required, in order to obtain a larger thermal exchange surface between the media. The fins and cavities can be used simultaneously, in the shape of cavities with fins. In this sense, the study of cavities became an important theme of works, in which the optimization of the geometries with the objective of favoring the heat transfer is desired. Thus, studies related to heat transfer in cavities have been continuously performed (Iwatsu and Hyun, 1995; Peng and Davidson, 1995; Cheng and Liu, 2010; Dos Santos et al., 2011; Lorenzini et al., 2015).

Applying the Constructal Design method is one way to improve the performance of thermal systems. This method is based on the Constructal Theory, which states that the geometry of all flow systems follows a physical principle - the Constructal Law.
This law is not a statement of optimization, maximization, minimization or any other form of end or final destination. It refers to the direction of evolution in time, stating that the designs of the flow systems are dynamic and not statics. According to the Constructal Law, for a finite-size flow system to persist in time (to live), its configurations must change in time such that it provides easier and easier access to its currents (fluid, energy, species, etc.) (Bejan, 2000; Bejan and Lorente, 2008). This is the physical principle employed by nature for the geometric formation of its flow systems, as in rivers, trees and animals (Bejan and Zane, 2012). This same principle can be used in the study of geometries in various engineering equipment, such as heat exchangers, fuel cells, etc. (Bejan and Lorente, 2006). Constructal Theory has been applied and has proved adequate for solving problems related to the search of geometries that improve the performance of fins and cavities with heat transfer (Rocha et al., 2005; Rocha et al., 2010; Lorenzini et al., 2011; Dos Santos et al., 2013; Estrada et al., 2015).

Thus, this paper purposes to investigate numerically, through the Constructal Design method, a system that combines a square cavity with a sliding upper wall and a heated triangular fin. The objective is to evaluate the influence of the triangular fin geometry on the average Nusselt number on its surface subjected to the mixed convection effect. In addition, it seeks to obtain the optimum geometry that maximizes heat transfer between the surface of the fin and the surrounding fluid. The Constructal Design method consists in the imposition of constraints, usually fixing areas or volumes, and giving freedom for geometry to be varied, in order to achieve an indicator of performance (Dos Santos et al., 2009).

The numerical solution of conservation equations of mass, momentum and energy are solved based on the Finite Volume Method (FVM), using the commercial fluid dynamics software FLUENT ${ }^{\circledR}$ (FLUENT, 2007). The geometry and the mesh of the computational domain were developed in the GAMBIT $^{\circledR}$ (GAMBIT, 2006).

\section{PROBLEM DESCRIPTION}

The main purpose of this study is to evaluate the geometries that lead to the maximization of the average Nusselt number calculated over the heated surface of the fin. The domain is considered twodimensional and it is depicted in Figure 1. The fluid flow is driven by the imposition of a field of velocities generated by the movement of the upper moving wall of the cavity, which moves with dimensionless velocities on the axis $\mathrm{x}\left(\mathrm{u}^{*}=1\right)$ and $\mathrm{y}$ $\left(\mathrm{v}^{*}=0\right)$. The velocity of the top plate is taken as reference for the computation of the Reynolds number. This plate presents non-slip and impermeability boundary conditions with an imposed 
velocity $\mathrm{V}$ and it has the lowest dimensionless temperature (Dirichlet boundary condition) of $\mathrm{T}^{*}=0$. In the region of the fin, the dimensionless prescribed temperature is $\mathrm{T}^{*}=1$ and non-slip and impermeability is employed. Finally, the lateral and inferior walls of the cavity are considered stationary and adiabatic (Neumann boundary condition) for fluid dynamic and thermal fields, respectively. The fluid properties are considered constant. To tack into account the effect of density variation it is considered the Boussinesq approximation. Moreover, the flow is considered incompressible and at the steady state.

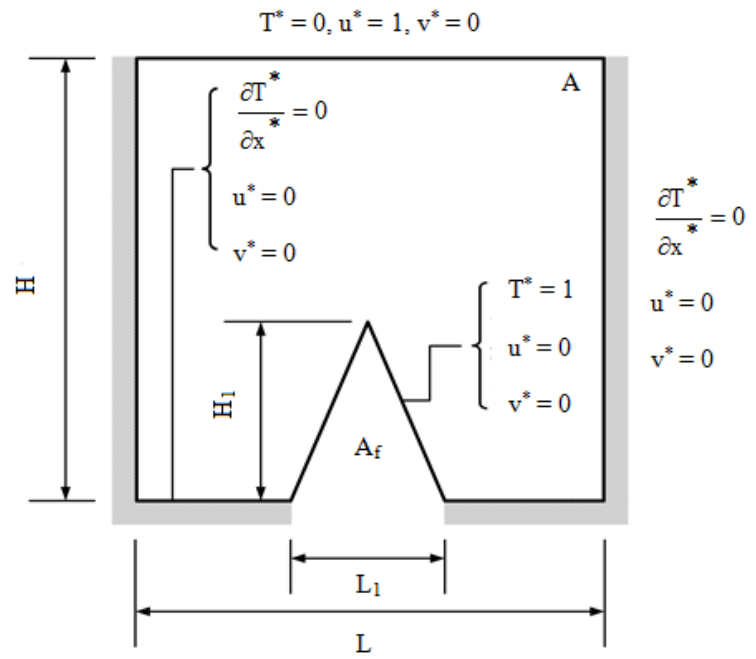

Figure 1. Domain of triangular fin inserted in the lid-driven rectangular cavity submitted to mixed convective flow.

In the geometric analysis, the Constructal Design method is used to determine the constraints, the degrees of freedom and the objective in the evaluation of the system (Bejan, 2000; Bejan and Lorente, 2008). The domain is illustrated in Fig. 1. The geometry has two constraints: the total area of the cavity (A) and the area occupied by the fin inside the cavity $\left(A_{f}\right)$, given, respectively by:

$$
\begin{gathered}
A=H \cdot L \\
A_{f}=\frac{H_{1} \cdot L_{1}}{2}
\end{gathered}
$$

A dimensionless relationship between the cavity area (A) and the fin area $\left(\mathrm{A}_{\mathrm{f}}\right)$ can be defined by the following equation:

$$
\phi=\frac{\mathrm{A}_{\mathrm{f}}}{\mathrm{A}}
$$

Thereby, it is possible to define the geometry of the system for any value of $\phi$, representing the fraction of the area occupied by the fin relative to the area of the cavity. The degrees of freedom for this study will be evaluated through the relation between the height and the length of the cavity $(\mathrm{H} / \mathrm{L})$, which is considered constant and equal to unity (square cavity, $\mathrm{H} / \mathrm{L}=1$ ); and by the ratio between the height and length of the fin $\left(\mathrm{H}_{1} / \mathrm{L}_{1}\right)$. It is investigated the ratio $\mathrm{H}_{1} / \mathrm{L}_{1}$ that maximizes the average Nusselt number for different values the $\phi$. The properties of the fluid and the flow for all the simulations are presented in Table 1. For all the geometric configurations, the flows were simulated with $\mathrm{Re}_{\mathrm{H}}=10^{2}, \mathrm{Ra}_{\mathrm{H}}=10^{4}$ and $\mathrm{Pr}=$ 0.71 , where $\operatorname{Re}_{H}$ is the Reynolds number based on the height of the cavity; $\mathrm{Ra}_{\mathrm{H}}$ is the Rayleigh number based on the height of the cavity and Pr is the Prandtl number $(v / \alpha)$. The dimensionless parameters will be properly defined in the mathematical modeling of the problem.

Table 1. Fluid and flow properties.

\begin{tabular}{|c|c|c|}
\hline Properties & Magnitude & Units \\
\hline $\mathrm{Pr}$ & 0.71 & - \\
\hline $\mathrm{k}$ & 0.56 & $\mathrm{~W} /(\mathrm{m} . \mathrm{K})$ \\
\hline$\mu$ & $1.77 \times 10^{-2}$ & $\mathrm{~kg} /(\mathrm{m} . \mathrm{s})$ \\
\hline $\mathrm{C}_{\mathrm{p}}$ & 1.00 & $\mathrm{~J} /(\mathrm{kg} . \mathrm{K})$ \\
\hline$\rho$ & Boussinesq & $\mathrm{kg} / \mathrm{m}^{3}$ \\
\hline$\alpha$ & $2.50 \times 10^{-2}$ & $\mathrm{~m}^{2} / \mathrm{s}$ \\
\hline$\beta$ & 0.4523 & $\mathrm{~K}^{-1}$ \\
\hline
\end{tabular}

\section{MATHEMATICAL AND NUMERICAL} MODELING

\section{Mathematical Modeling}

The conservation equations of continuity, momentum (in $\mathrm{x}$ and $\mathrm{y}$ directions) and energy for steady state, incompressible and with constant thermophysical properties for a mixed convection problem are given, respectively, by:

$$
\frac{\partial u}{\partial x}+\frac{\partial v}{\partial y}=0
$$

$$
\begin{gathered}
u \frac{\partial u}{\partial x}+v \frac{\partial u}{\partial y}=-\frac{1}{\rho} \frac{\partial P}{\partial x}+v\left(\frac{\partial^{2} u}{\partial x^{2}}+\frac{\partial^{2} u}{\partial y^{2}}\right) \\
u \frac{\partial u}{\partial x}+v \frac{\partial u}{\partial y}= \\
-\frac{1}{\rho} \frac{\partial P}{\partial y}+v\left(\frac{\partial^{2} v}{\partial x^{2}}+\frac{\partial^{2} v}{\partial y^{2}}\right)-g \beta\left(T-T_{\infty}\right) \\
u \frac{\partial T}{\partial x}+v \frac{\partial T}{\partial y}=\alpha\left(\frac{\partial^{2} T}{\partial x^{2}}+\frac{\partial^{2} T}{\partial y^{2}}\right)
\end{gathered}
$$

in which $\rho$ is the fluid density $\left(\mathrm{kg} / \mathrm{m}^{3}\right) ; \beta$ is the thermal expansion coefficient $\left(\mathrm{K}^{-1}\right) ; \quad v$ is the kinematic viscosity $\left(\mathrm{m}^{2} / \mathrm{s}\right)$; $\mathrm{u}$ and $\mathrm{v}$ are the velocities in $\mathrm{x}$ and $\mathrm{y}$ direction $(\mathrm{m} / \mathrm{s}) ; \mathrm{x}$ and $\mathrm{y}$ are the spatial 
coordinates $(\mathrm{m})$; $\mathrm{P}$ is the pressure $(\mathrm{Pa}) ; \mathrm{T}$ is the absolute temperature $(\mathrm{K}) ; \mathrm{T}_{\infty}$ is the reference temperature $(\mathrm{K})$; $\alpha$ is the thermal diffusivity $\left(\mathrm{m}^{2} / \mathrm{s}\right)$; and $\mathrm{g}$ is the gravitation acceleration in $\mathrm{y}$ direction $\left(9,81 \mathrm{~m} / \mathrm{s}^{2}\right)$. The thermal diffusivity is given by:

$$
\alpha=\frac{\mathrm{k}}{\rho \cdot \mathrm{C}_{\mathrm{P}}}
$$

In order to generalize the results, the problem is treated in dimensionless form. The spatial, thermal and velocity variables of the system are defined by:

$$
\begin{gathered}
\left(\mathrm{x}^{*}, \mathrm{y}^{*}, \mathrm{H}^{*}, \mathrm{H}_{1}^{*}, \mathrm{~L}^{*}, \mathrm{~L}_{1}^{*}\right)=\frac{\left(\mathrm{x}, \mathrm{y}, \mathrm{H}, \mathrm{H}_{1}, \mathrm{~L}, \mathrm{~L}_{1}\right)}{\mathrm{A}^{1 / 2}} \\
\mathrm{~T}^{*}=\frac{\mathrm{T}-\mathrm{T}_{\min }}{\mathrm{T}_{\max }-\mathrm{T}_{\min }} \\
\left(\mathrm{u}^{*}, \mathrm{v}^{*}\right)=\frac{(\mathrm{u}, \mathrm{v})}{\mathrm{u}_{\max }}
\end{gathered}
$$

Then, the dimensionless lengths that define the system geometry can be rewritten as:

$$
\begin{gathered}
L^{*}=\sqrt{\frac{1}{\left(H^{*} / L^{*}\right)}} \\
\mathrm{H}^{*}=\frac{1}{\mathrm{~L}^{*}} \\
\mathrm{~L}_{1}^{*}=\sqrt{\frac{2 \phi}{\left(\mathrm{H}_{1}^{*} / \mathrm{L}_{1}^{*}\right)}} \\
\mathrm{H}_{1}^{*}=\frac{2 \phi}{\square \mathrm{L}_{1}^{*}}
\end{gathered}
$$

The convective and conductive heat flux per unit area are defined respectively by (Bejan, 2013):

$$
\mathrm{q}^{\prime \prime}=\mathrm{h}\left(\mathrm{T}-\mathrm{T}_{\infty}\right) \text { and } \mathrm{q}^{\prime \prime}=-\mathrm{k}\left(\frac{\partial \mathrm{T}}{\partial \mathrm{y}}\right)_{\mathrm{y}=0}
$$

where $k$ is the fluid thermal conductivity (W/m.K).

Combining the Eqs. (16) it is possible to obtain the heat transfer coefficient:

$$
h=\frac{-k\left(\frac{\partial T}{\partial y}\right)_{y=0}}{\left(T-T_{\infty}\right)}
$$

The Nusselt number (based on the cavity height) represents the dimensionless heat transfer coefficient, defined as the ratio between the convective and conductive heat transfer (Bejan, 2013):

$$
\mathrm{Nu}_{\mathrm{H}}=\frac{\mathrm{h} \cdot \mathrm{H}}{\mathrm{k}}
$$

in which $H$ is the characteristic length (m).

The average Nusselt number is calculated by integrating the local Nusselt number over the surface:

$$
\overline{\mathrm{Nu}}_{\mathrm{H}}=\frac{1}{\mathrm{~S}^{*}} \int_{\mathrm{S}^{*}} \mathrm{Nu}_{\mathrm{H}} \mathrm{dS}
$$

in which $S$ is the surface on which the fluid flows $\left(\mathrm{m}^{2}\right)$ and $S^{*}=S / A$.

In order to characterize correctly the boundary layer phenomenon, the Reynolds number (based on the cavity height) is introduced, allowing identifying a value for the transition from the laminar flow to turbulent flow. This dimensionless parameter is defined as:

$$
\operatorname{Re}_{\mathrm{H}}=\frac{\rho \cdot \mathrm{V} \cdot \mathrm{H}}{\mu}
$$

where $\mathrm{V}$ is the velocity of the upper moving wall of the cavity $(\mathrm{m} / \mathrm{s})$.

The Rayleigh number (based on the cavity height) is used to define the importance of the natural convection in the heat transfer of the fluid. Magnitudes under a critical value indicate the predominance of the diffusion on the heat transfer; for Ra over the critical value, means the convection is dominant. This dimensionless parameter accounts the buoyancy force effects, indicating the influence of the natural convection over the mixed convection regime. The Rayleigh number is given by (Bejan, 2013):

$$
\mathrm{Ra}_{\mathrm{H}}=\frac{g \beta\left(\mathrm{T}_{\mathrm{S}}-\mathrm{T}_{\text {máx }}\right) \mathrm{H}^{3}}{v \alpha}
$$

\section{Numerical Modeling}

For the numerical analysis, a non-uniform twodimensional mesh (in the $\mathrm{x}$ and $\mathrm{y}$ directions) with triangular volumes is adopted, which was generated using the software GAMBIT. The numerical solution of the Eqs. (4)-(7) were obtained through commercial computational fluid dynamics software FLUENT, that is reasoned on the finite volume method. This method consists of making balances on a control volume created from finite volumes (Maliska, 2004). For the density variation, it is used the Boussinesq model (Kays and Crawford, 1980), in order to account for buoyancy effects. Furthermore, the discretization mode is the first order upwind for the momentum, energy and continuity equations, while 
the standard mode is used for the pressure. Besides, the pressure-velocity coupling is made using the SIMPLEC algorithm. For the numerical residuals, the convergence criteria is defined as maximum of $10^{-6}$ for the continuity and momentum equations and $10^{-8}$ for the energy.

The adopted mesh was determined by means of successive refinements. Therefore, the mesh quality analysis was carried out, in order to determine the number of finite volumes necessary for the mesh to not influence the results of the study. The mesh was considered adequate when the relative deviation of the average Nusselt number between meshes of different volume numbers is less than $1 \%$. The relative percentage deviation between the results is obtained by the following expression:

$$
\text { Deviation } \overline{\mathrm{Nu}_{\mathrm{H}}}=100 \cdot \frac{\left|\overline{\mathrm{Nu}}_{(\mathrm{j})}-\overline{\mathrm{Nu}}_{(\mathrm{j}+1)}\right|}{\overline{\mathrm{Nu}}_{(\mathrm{j})}}<1 \%
$$

where the indexes $(j)$ and $(j+1)$, represent, respectively, the results for the mesh to be evaluated and the mesh with the largest number of volumes.

Table 2 shows the results of the mesh quality analysis for the flow with $\mathrm{Ra}_{\mathrm{H}}=10^{4}, \mathrm{Pr}=0.71$ and $\operatorname{Re}_{\mathrm{H}}=10^{2}$. For all the meshes tested, it is considered $\phi=0.5$ and $\mathrm{H}_{1} / \mathrm{L}_{1}=0.3$.

Table 2. Mesh independence analysis.

\begin{tabular}{|c|c|c|}
\hline Volumes & $\overline{\mathrm{Nu}_{\mathrm{H}}}$ & Deviation (\%) \\
\hline 5,040 & 4.1025 & 1.3821 \\
\hline 11,000 & 4.1593 & 1.0427 \\
\hline $\mathbf{2 0 , 5 0 0}$ & $\mathbf{4 . 2 0 2 6}$ & $\mathbf{0 . 7 9 0 7}$ \\
\hline 40,750 & 4.2359 & - \\
\hline
\end{tabular}

After the tests, it was verified that the mesh of 20,500 volumes can be considered appropriate for the proposed study, presenting a deviation of approximately $0.79 \%$ in relation to the mesh with the largest number of volumes, attending, thus, the criterion of precision defined initially. The model used in this study has already been validated in previous studies (Dos Santos et al., 2013; Machado, 2014) for different fin geometric and flows.

\section{RESULTS AND DISCUSSION}

Flow and temperature fields were simulated to determine the aspect ratio $\mathrm{H}_{1}{ }^{*} / \mathrm{L}_{1}{ }^{*}$ that leads to maximization of the average Nusselt number calculated along the surface of the fin. The fraction of area $(\phi)$ occupied by the fin in relation to the cavity also had its value varied, according to the range 0.01 $\leq \phi \leq 0.30$. For all the geometric configurations, $\operatorname{Re}_{\mathrm{H}}$ $=10^{2}, \mathrm{Ra}_{\mathrm{H}}=10^{4}$ and $\mathrm{Pr}=0.71$.

From Figure 2, it can be seen how the average Nusselt number $\left(\overline{\mathrm{Nu}_{\mathrm{H}}}\right)$, obtained on the fin surface, behaves as a function of the variation of the ratio $\mathrm{H}_{1}{ }^{*} / \mathrm{L}_{1}{ }^{*}$ for different values of $\phi$. It is observed that the curves present a very similar behavior, having an optimum ratio $\mathrm{H}_{1}{ }^{*} / \mathrm{L}_{1}{ }^{*}$ in relation to the average Nusselt number $\left(\overline{\mathrm{Nu}_{\mathrm{H}}}\right)$ for all values studied. Thus, it is noted that, with the increase of the ratio $\mathrm{H}_{1}{ }^{*} / \mathrm{L}_{1}{ }^{*}$, there is a growth of the $\overline{\mathrm{Nu}_{\mathrm{H}}}$ values up to the maximum point, so that, as from this maximum, the $\overline{\mathrm{Nu}_{\mathrm{H}}}$ values tend to decrease with the increase of the aspect ratio $\mathrm{H}_{1}{ }^{*} / \mathrm{L}_{1}{ }^{*}$. It is an exception for this behavior the result for $\phi=0.3$, in which the maximum value of $\overline{\mathrm{Nu}_{\mathrm{H}}}$ is obtained for the smallest value of $\mathrm{H}_{1}{ }^{*} / \mathrm{L}_{1}{ }^{*}$, i.e., the minimum physically possible value for this configuration.

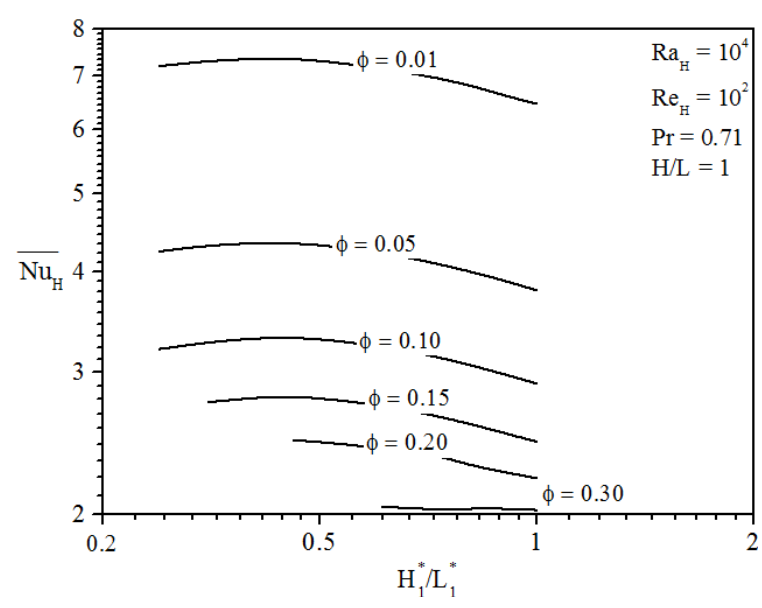

Figure 2. Behavior of aspect ratio $\mathrm{H}_{1}{ }^{*} / \mathrm{L}_{1}{ }^{*}$ for different values of $\phi$.

The higher values of $\overline{\mathrm{Nu}_{\mathrm{H}}}$ were obtained for the configuration of $\phi=0.01$, i.e, for the smaller fraction of area occupied by the fin in relation to the cavity. It is also noted, observing the Fig. 2, a decrease in the heat transfer in the system with increasing values of $\phi$. For a better understanding of this phenomenon, it is presented the Fig. 3, which shows the temperature fields for the optimized cases of $\mathrm{H}_{1}{ }^{*} / \mathrm{L}_{1}{ }^{*}$ (represented by $\left(\mathrm{H}_{1}{ }^{*} / \mathrm{L}_{1}{ }^{*}\right)_{\mathrm{o}}$ ) for some values of $\phi$ studied. From Figure 3, it is perceived the presence of larger temperature gradients around the fins for smaller values of $\phi$, favoring the heat transfer.

In the configuration that is obtained the best thermal performance, $\phi=0.01$, it is observed that the study of the aspect ratio $\mathrm{H}_{1}{ }^{*} / \mathrm{L}_{1}{ }^{*}$ leads to a gain in the thermal performance of approximately $15 \%$ of the optimized case $\left(\left(\mathrm{H}_{1}{ }^{*} / \mathrm{L}_{1}{ }^{*}\right)_{0}=0.42\right)$ in relation to the case of lower performance $\left(\mathrm{H}_{1}{ }^{*} / \mathrm{L}_{1}{ }^{*}=1\right)$, in the range of $\mathrm{H}_{1}{ }^{*} / \mathrm{L}_{1}{ }^{*}$ studied. For the others values of $\phi$ analyzed, the thermal gain of the optimum configurations allowed a heat transfer performance of more than $10 \%$ in relation to the cases of lower performance. 


$$
\begin{aligned}
& \mathrm{T}^{*}=1 \\
& \mathrm{~T}^{*}=0
\end{aligned}
$$

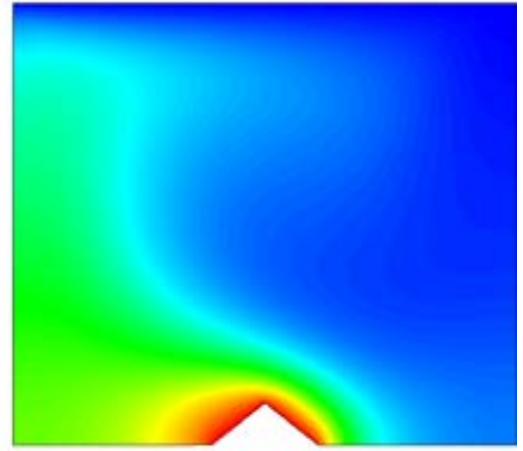

$\phi=0.01$

$\left(\mathrm{H}_{1}{ }^{*} / \mathrm{L}_{1}{ }^{*}\right)_{0}=0.42$
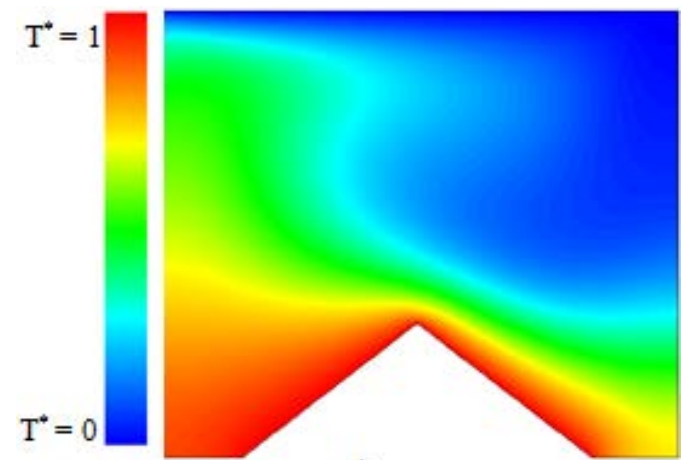

$\phi=0.10$

$\left(\mathrm{H}_{1}^{*} / \mathrm{L}_{1}{ }^{*}\right)_{0}=0.44$

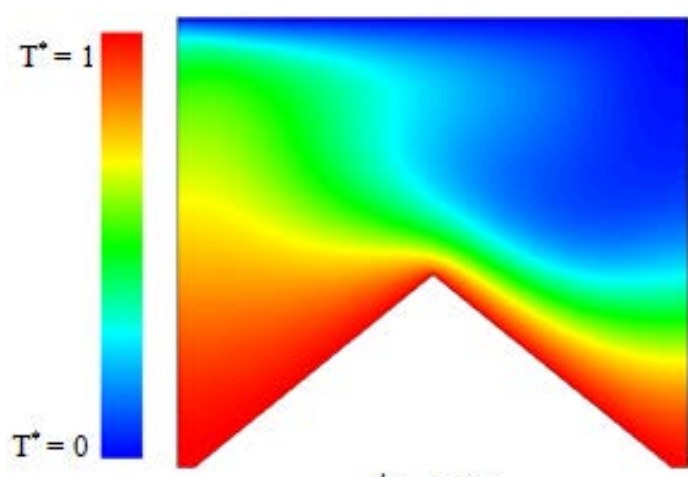

$\phi=0.20$

$\left(\mathrm{H}_{1}^{*} / \mathrm{L}_{1}^{*}\right)_{0}=0.46$

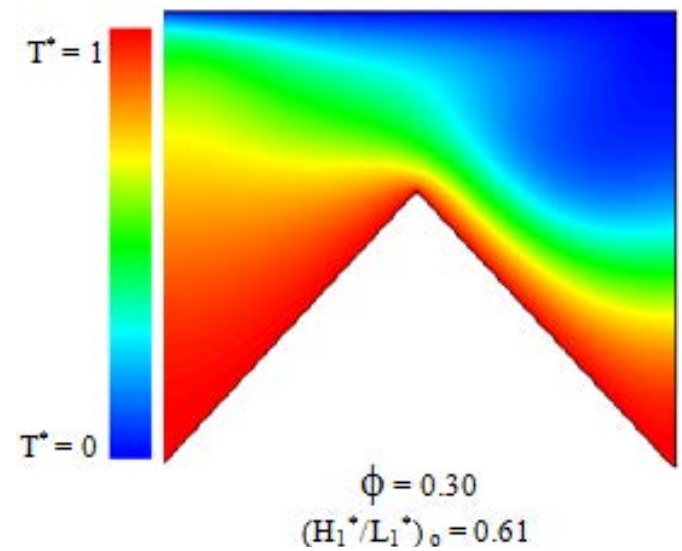

Figure 3. Temperature fields for $\left(\mathrm{H}_{1}{ }^{*} / \mathrm{L}_{1}{ }^{*}\right)_{\mathrm{o}}$ and for different values of $\phi$.
The optimal results obtained are shown in Fig. 4, which shows the behavior of $\left(\overline{\mathrm{Nu}_{\mathrm{H}}}\right)_{0}$ and the aspect ratio $\left(\mathrm{H}_{1}{ }^{*} / \mathrm{L}_{1}{ }^{*}\right)_{0}$ as function of $\phi$. The optimum average Nusselt number $\left(\overline{\mathrm{Nu}_{\mathrm{H}}}\right)_{0}$ decreases as the $\phi$ values increase, phenomenon caused by the lower temperature gradients around the fin for the cases of greater fraction of areas $(\phi)$. On the other hand, the values of $\left(\mathrm{H}_{1}{ }^{*} / \mathrm{L}_{1}{ }^{*}\right)_{0}$ obtained show a regular behavior as $\phi$ is varied, which can be explained by the similar behavior of the fluid layers of the different cases studied, caused by the low Reynolds number adopted in this work.

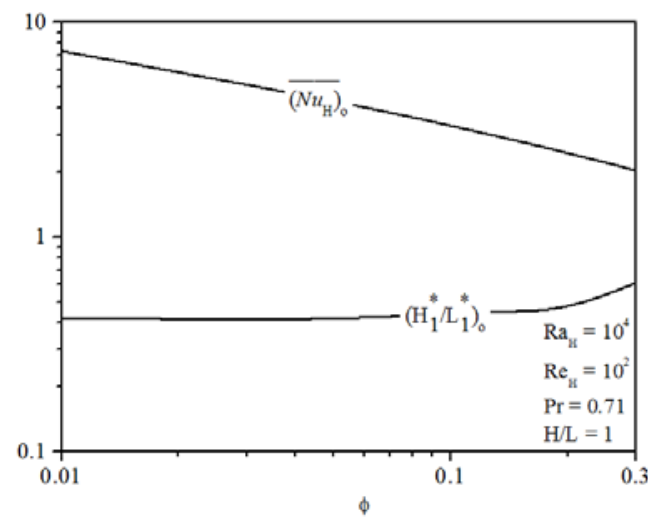

Figure 4. Behavior of the $\left(\overline{\mathrm{Nu}_{\mathrm{H}}}\right)_{0}$ and the aspect ratio $\left(\mathrm{H}_{1}{ }^{*} / \mathrm{L}_{1}{ }^{*}\right)_{0}$ as a function of $\phi$.

Table 3 shows the values obtained for the optimal Nusselt number $\left(\overline{\mathrm{Nu}_{\mathrm{H}}}\right)_{0}$ and the optimal aspect ratio $\left(\mathrm{H}_{1}{ }^{*} / \mathrm{L}_{1}{ }^{*}\right)_{0}$ for the cases of $\phi$ studied. Through the optimum results obtained, it is possible to verify that the system adapts its optimal configuration to each value of $\phi$ studied, in order to provide the best flow architecture to comply with the thermal objective, being in accordance with the principles of the Constructal Law.

Table 3. Optimum results obtained in the study for $\mathrm{Ra}_{\mathrm{H}}=10^{4}, \operatorname{Pr}=0.71$ and $\mathrm{Re}_{\mathrm{H}}=10^{2}$.

\begin{tabular}{|c|c|c|}
\hline$\varphi$ & $\left(\overline{\mathrm{Nu}_{\mathrm{H}}}\right)_{\mathrm{o}}$ & $\left(\mathrm{H}_{1}{ }^{*} / \mathrm{L}_{1}{ }^{*}\right)_{\mathrm{o}}$ \\
\hline 0.01 & 7.2772 & 0.42 \\
\hline 0.05 & 4.3108 & 0.41 \\
\hline 0.10 & 3.2903 & 0.44 \\
\hline 0.15 & 2.7961 & 0.45 \\
\hline 0.20 & 2.4677 & 0.46 \\
\hline 0.30 & 2.0379 & 0.61 \\
\hline
\end{tabular}

\section{CONCLUSIONS}

This article evaluated numerically, through the Constructal Design method, the influence of the aspect ratio $\mathrm{H}_{1}{ }^{*} / \mathrm{L}_{1}{ }^{*}$ on the heat transfer between the heated triangular fin inserted into a rectangular cavity and the surrounding fluid, subjected to the mixed convection effect. The flow was assumed being 
steady state, laminar, two-dimensional and incompressible. The fluid properties were considered constant, except the density, which was varied according to Boussinesq approximation. The ratio of areas $\phi$ was another parameter studied.

The flow regime was driven by the imposition of a velocity field generated by the movement of the moving wall of the cavity, as well by the natural movement of fluid caused by the temperature differences present in the flow. Flows characterized by $\mathrm{Ra}_{\mathrm{H}}=10^{4}$ and $\mathrm{Re}_{\mathrm{H}}=10^{2}$ were evaluated. It was searched for the optimum aspect ratio $\mathrm{H}_{1}{ }^{*} / \mathrm{L}_{1}{ }^{*}$ of the triangular fin inserted in the cavity in order to obtain the largest Nusselt number $\left(\overline{\mathrm{Nu}_{\mathrm{H}}}\right)$ for different values of $\phi$.

The computational domain and its discretization were elaborated through non-uniform triangular volumes. The mesh was evaluated through a quality analysis, where the behavior of the average Nusselt number $\left(\overline{\mathrm{Nu}_{\mathrm{H}}}\right)$ was verified around the triangular fin for meshes with different number of volumes. The mesh used in the simulations presented a deviation in relation to the mesh with a greater number of volumes less than $1 \%$, justifying its use in the work. The solution obtained with the mesh adopted was qualitatively adequate (temperature fields).

Thus, it was possible to analyze, through this study, the behavior of the phenomenon of heat transfer through the variation of the geometry of the studied system, so that geometric recommendations were obtained by varying the aspect ratio $\mathrm{H}_{1}{ }^{*} / \mathrm{L}_{1}{ }^{*}$ for different values of $\phi$. The Construtal Design method proved to be efficient to obtain optimal configurations for the proposed geometry, so that the optimal results obtained in this work presented a $15 \%$ superior performance in relation to the non-optimized cases, so that the heat flow resistances of the optimum system configurations were balanced. In addition, it was verified that the heat transfer was strongly affected by the variation of the fraction of area $(\phi)$.

\section{ACKNOWLEDGEMENTS}

The authors thank to the CNPq and CAPES for financial support, as well as the universities UFRGS and FURG that helped in the elaboration of this paper.

\section{REFERENCES}

Bejan, A., 2013, Convection Heat Transfer, New York, John Wiley \& Sons.

Bejan, A., 1993, Heat Transfer, Vol. 1, New York, John Wiley \& Sons.

Bejan, A., 2000, Shape and Structure, from Engineering to Nature, Cambridge, United Kingdom: Cambridge University Press.

Bejan, A., and Kraus, A. D., 2003, Heat
Transfer Handbook, Vol. 1. New York, John Wiley \& Sons.

Bejan, A., and Lorente, S., 2006, Constructal Theory of Generation of Configuration in Nature and Engineering, Journal of Applied Physics, Vol. 100, pp. 041301.

Bejan, A., and Lorente, S., 2008, Design with Constructal Theory, New York, John Wiley \& Sons.

Bejan, A., and Zane, J. P., 2012, Design in Nature, New York, Doubleday.

Çengel, Y. A., and Ghajar, A. J., 2009, Transferência de Calor e Massa: uma Abordagem Prática, São Paulo, AMGH LTDA. (in Portuguese)

Cheng, T. S., and Liu, W. H., 2010, Effect of Temperature Gradient Orientation on the Characteristics of Mixed Convection Flow in a lidDriven Square Cavity, Computers \& Fluids, Vol. 39, No. 6, pp. 965-978.

Maliska, C. R., 2004, Transferência de Calor e Mecânica dos Fluidos Computacional, Rio de Janeiro, LTC. (in Portuguese)

Dos Santos, E. D., Dall’Agnol, A., Petry, A. P., and Rocha, L. A. O., 2009, Heat Transfer Optimization of Cross-Flow Over Assemblies of Bluff Bodies Employing Constructal Principle, in: Proc. 20th International Congress of Mechanical Engineering, Gramado, Brasil, pp. 1-8.

Dos Santos, E. D., Isoldi, L. A., Souza, J. A., Goulart, M. M., Rodrigues, M. K., Seibt, F. M., Souza, R. V., and Rocha, L. A. O., 2013, Constructal Design of a Rectangular Fin Intruded Into Forced Convective Lid-Driven Cavity Flows, in Bejan, A., Lorente, S., and Zhang, H., eds, proceedings of Constructal Law Conference (CLC 2013), Nanjing, China, Vol. 1, pp. 126-134.

Dos Santos, E. D., Piccoli, G. L., França, F. H. R., and Petry, A. P., 2011, Analysis of Mixed Convection in Transient Laminar and Turbulent Flows in Driven Cavities, International Journal of Heat and Mass Transfer, Vol. 54, No. 21, pp. 45854595.

Estrada, E. S. D., Fagundes, T. M., Isoldi, L. A., Dos Santos, E. D., Xie, G., and Rocha, L. A. O., 2015, Constructal Design Associated to Genetic Algorithm of Asymmetric V-Shaped Pathways, Journal of Heat Transfer, Vol. 137, No. 6, pp. 061010-1 - 061010-7.

FLUENT (version 6.3.26), 2007, ANSYS, Inc.

GAMBIT (version 2.4.6), 2006, ANSYS, Inc.

Iwatsu, R., and Hyun, J. M., 1995, ThreeDimensional Driven-Cavity Flows with a Vertical Temperature Gradient, International Journal of Heat and Mass Transfer, Vol. 38, No. 18, pp. 3319-3328.

Kays, W. M., and Crawford, M. E., 1980, Convective Heat and Mass Transfer, New York, McGraw-Hill.

Lorenzini, G., Biserni, C., Isoldi, L. A., dos Santos, E. D., and Rocha, L. A., 2011, Constructal Design Applied to the Geometric Optimization of YShaped Cavities Embedded in a Conducting Medium, 
Journal of Electronic Packaging, Vol. 133, No. 4, 041008-1 - 041008-8.

Lorenzini, G., Estrada, E. D. S. D., dos Santos, E. D., Isoldi, L. A., and Rocha, L. A. O., 2015, Constructal Design of Convective Cavities Inserted Into a Cylindrical Solid Body for Cooling, International Journal of Heat and Mass Transfer, Vol. 83, pp. 75-83.

Machado, B. D. S., 2014, Constructal Design de Aleta Retangular Inserida em Cavidade com Superfície Superior Deslizante sob Efeito de Convecção Mista, Master Thesis, PROMEC-UFRGS, Porto Alegre, RS. (in Portuguese)

Ozisik, M. N., 1993, Heat Conduction, New York, John Wiley \& Sons.

Peng, S. H., and Davidson, L., 2001, Large Eddy Simulation for Turbulent Buoyant Flow in a Confined Cavity, International Journal of Heat and Fluid Flow, Vol. 22, No. 3, pp. 323-331.

Rocha, L. A., Lorenzini, E., and Biserni, C., 2005, Geometric Optimization of Shapes on the Basis of Bejan's Constructal Theory, International Communications in Heat and Mass Transfer, Vol. 32, No. 10, pp. 1281-1288.

Rocha, L. A. O., Lorenzini, G., Biserni, C., and Cho, Y., 2010, Constructal Design of a Cavity Cooled by Convection, International Journal of Design \& Nature and Ecodynamics, Vol. 5, No. 3, pp. 212-220. 